\title{
The Design and Engineering of Mobile Data Services: Developing an Ontology Based on Business Model Thinking
}

\author{
Mutaz M. Al-Debei and Guy Fitzgerald \\ Department of Information Systems and Computing, \\ Brunel University \\ Middlesex, Uxbridge, \\ London UB8 3PH, United Kingdom
}

\begin{abstract}
This paper addresses the design and engineering problem related to mobile data services. The aim of the research is to inform and advise mobile service design and engineering by looking at this issue from a rigorous and holistic perspective. To this aim, this paper develops an ontology based on business model thinking. The developed ontology identifies four primary dimensions in designing business models of mobile data services: value proposition, value network, value architecture, and value finance. Within these dimensions, $15 \mathrm{key}$ design concepts are identified along with their interrelationships and rules in the telecommunication service business model domain and unambiguous semantics are produced. The developed ontology is of value to academics and practitioners alike, particularly those interested in strategic-oriented IS/IT and business developments in telecommunications. Employing the developed ontology would systemize mobile service engineering functions and make them more manageable, effective, and creative. The research approach to building the mobile service business model ontology essentially follows the design science paradigm. Within this paradigm, we incorporate a number of different research methods, so the employed methodology might be better characterized as a pluralist approach.
\end{abstract}

Keywords: Business model, service design and engineering, mobile data services, ontology, design science, mobile technology, telecommunications.

\section{Introduction}

The mobile telecommunications business is undergoing major changes, driven by innovative technologies, globalization, and deregulation. Recent technological advances in telecommunications are bringing enormous change to the way mobile business is conducted and the way in which we live our lives. This is apparent from the shift of the industry from mainly voice to one that is mostly about data (Dodourova 2003). At the same time, globalization and deregulation are removing many of the legacy barriers to telecommunications and providing environment more amenable to sustainable competition. 
The implications of this transformation have changed the business rules of the telecommunications industry. Nowadays, the major challenges faced by telecommunications providers (from now on shortened to telecoms) are the shifts from one simple service to a portfolio of mainly convergent services (e.g., integration of voice, data, and Internet), from no or few affiliations to multiple partnerships, from simple and linear links to complex relationships (Olla and Patel 2002), from homogeneous to heterogeneous customer demands, and from customers consuming modest services to customers continuously presuming advanced, high quality services (Kim et al. 2008).

In response to these challenges, telecoms have been compelled to repackage their business; that is, overhauling the traditional way in which mobile services are designed and developed. This is particularly pertinent now, with the saturation of the voice market and the credit crunch. For telecoms to get their strategies right is critical to success as inappropriate decisions can have major adverse effects on performance. However, achieving this has proven difficult. One key indicator is that revenues generated from services other than voice telephony and SMS are below expectations, although the number of mobile users worldwide is continuously increasing (ITU 2009). In our context, the problem is clearly related to the design of appropriate mobile data services. When it comes to service design and engineering (see Bullinger et al. 2003), telecoms are facing many issues that are hindering their progress, including

(1) The absence of a coherent framework. Telecoms services are not clearly defined; there is no unequivocal, comprehensive identification of the service related issues such as content, associated values and benefits, needed resources, target segments, financial designs, etc.

(2) Inappropriate organizational design. The structure, infrastructure, and/or technological architecture of telecoms are not designed to enable efficient development and launch of new services.

(3) Weak alignment among all organizational layers. The service model is not tightly consistent with the strategic objectives of telecoms or their operational processes, including their information systems.

Retrospectively, there is a significant need to inform and advise service design and engineering in the telecommunications sector by looking at this issue from an integrated and cohesive perspective. Services probably need to be developed or redeveloped using a comprehensive and effective approach, if they are to be successful. One element of this is the need for an innovative business model to be developed that focuses on the achievement of strategic outcomes by aligning ICT services. A business model has been described as a "logical story" (Magretta 2002), or a "blueprint" (Chesbrough and Rosenbloom 2002) that explains the "way of doing business" (Hamel 2000) so that strategic goals and objectives can be achieved.

For the purpose of achieving clarity and semantic preciseness in the design of service business models, this paper utilizes the ontology concept as it is an explicit and formal specification of key objects, relationships, and semantics of a particular domain (Chandrasekaran et al. 1999). In particular, we develop a novel ontology that rigorously identifies the service business model components, interrelationships, and their semantics in the context of mobile data services. 
The remainder of this paper is structured as follows. First, a theoretical background concerning business models and their role in service engineering is provided together with a discussion of ontologies and their functions in information systems. Next the design science research method for the ontological engineering approach that was undertaken is described. Thereafter, the constructed ontology is developed, showing its concepts (dimensions and elements), properties, and semantics. Finally, we summarize and outline the contributions of this paper.

\section{Theoretical Background}

\subsection{The Role of Business Models in Service Design and Engineering}

The business model concept, although much talked about, is somewhat fuzzy (Seddon et al. 2004; Seppänen and Mäkinen 2007) and researchers have defined it from different viewpoints. For example, Linder and Cantrell (2000) portray the business model as a tool that explains how business organizations generate revenues, while Andersson et al. (2006) describe the business model as a mechanism that makes the relationship between business actors more explicit. In an attempt to clarify this situation, Al-Debei et al. (2008a) have analytically synthesized the related literature, and define a business model as an

abstract representation of an organization, be it conceptual, textual, and/or graphical, of all core interrelated architectural, co-operational, and financial arrangements designed and developed by an organization presently and in the future, as well as all core products and/or services the organization offers, or will offer, based on these arrangements that are needed to achieve its strategic goals and objectives (pp. 8-9).

The extant literature in both business and information systems testifies to the importance of the business model concept to the success of companies, particularly those driven by ICTs. Examples of the domains where the concept has been utilized include mobile technology (e.g., Al-Debei and Avison 2010; Al-Debei et al. 2008b; Bouwman et al. 2008; Maitland 2005), eBusiness and eCommerce (e.g., Afuah and Tucci 2003; Gordjin and Akkermans 2001; Osterwalder et al. 2005), and other emerging industries where IT innovations and technologies are of importance (e.g., Ballon 2007; Hedman and Kalling 2003; MacInnes 2005).

The underlying principle behind this increasing interest is the conception that it not the technology itself, but rather the design of the business model, that actually determines success (Yuan and Zhang 2003), and allows high-technology companies to achieve their strategic outcomes by developing relevant and desired services and applications. For example, Chesbrough and Rosenbloom (2002) argue that "a successful business model creates a heuristic logic that connects technical potential with the realization of economic value" (p. 529). In line with this, Kamoun (2008) argues that the business model "becomes the blueprint of the way a business creates and captures value from new services, products, or innovations" (p. 638).

This is equally relevant to mobile data services. For example, the success of NTT DoCoMo's i-mode is primarily credited to its well-designed business model in action 


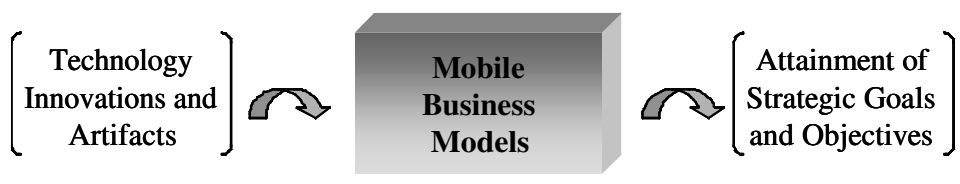

Fig. 1. The Business Model as a Mediating Construct

(Ratliff 2002) and the low adoption of WAP is argued to be mainly due to the absence of a feasible business model or its inappropriate configuration (Kumar et al. 2003; Sigurdson 2001).

Therefore, we consider the employment of business models, as a mediating construct between technological artifacts and the fulfilment of strategic outcomes, as highly applicable to mobile service design and engineering (see Figure 1).

\subsection{The Role of Ontologies}

Ontology is a term that has originated in philosophy and refers to the systematic explanation and study of the nature of existence. The term has been borrowed by the information systems and computing disciplines (e.g., Guarino and Welty 2002; Wand and Weber 1990) and changed somewhat, but despite its recent extensive use in these disciplines, the term has no universal definition.

Principally, the term ontology means one of two related things (Chandrasekaran et al. 1999). First, the term is used to refer to a body of knowledge or theory demonstrating a particular real world phenomenon. In its second, more practical sense, ontology refers to the shared and explicit specification and representation of classes of objects (i.e., concepts and vocabularies), properties (i.e., relationships), and semantics (i.e., meaning) of particular domains. One of the most cited definitions of ontology is by Gruber (1993), who defines it as an "explicit specification of a conceptualization" (p. 1). Conceptualization is what makes ontologies shareable as it refers to the meanings captured through concepts, not the terms themselves. Furthermore, conceptualization implies abstraction, which signifies that an ontology represents only knowledge regarded as core in the specific domain.

Ontology research has gained particular recognition in the area of information systems analysis and design (e.g., Wand and Weber 2002; Wyssusek 2004). Information systems that make use of explicit and formally defined ontologies have been described as ontology-driven systems (Guarino 1998). Such ontologies are referred to as IS ontologies (e.g., Smith 2003), or computational ontologies (e.g., Kishore and Sharman 2004). We hope that developing an ontology will enable the precise identification and categorization of the key concepts and relationships in the telecom services business model and produce unambiguous semantics of them.

\section{Research Methods}

The research paradigm followed here, concerned with analytically designing and developing a business model ontology for mobile data services, is that of design science (Hevner et al. 2004). 
Design artifacts are classified by March and Smith (1995), and anchored by Hevner et al. (2004), into constructs of vocabulary and symbols, models representing reality with appropriate levels of abstraction, methods in the form of algorithms and practices, and instantiations, which are implemented systems and/or their prototypes developed as proof-of-concepts. The developed ontology in this paper represents a model artifact that includes constructs. This ontology is produced using an approach developed by the authors, called OntoEng; that is, a design method for ontology engineering in the field of information systems. This method (OntoEng) and its application to build and evaluate the mobile service business model ontology are outlined in this paper and fully discussed elsewhere (see Al-Debei and Fitzgerald 2009).

Essentially, within the design science paradigm, the applied approach is best portrayed as a pluralist methodology, as different research methods are incorporated. A multimethod approach is beneficial because, as Mingers (2001) argues, results are richer and more reliable if different research methods are combined. We agree with Mingers since different, related research methods have their own advantages and drawbacks but, when appropriately combined, they can provide enhanced value. Based on the classification provided by Palvia et al. (2006), we now briefly discuss the various methods employed in this research.

\subsection{Qualitative Research: Interviews}

The current research utilizes empirical data as its main source. We conducted 18 semi-structured interviews with key practitioners (i.e., managers) in the telecommunications sector. Interviews were recorded and on average lasted about 90 minutes. The interviews were transcribed, verified, and then analyzed. The primary themes discussed with the interviewee managers included collaboration with value network actors, resource allocation and configuration, the creation of core competencies, costing and pricing, customer relationship management and intelligence, and other related services. The background and specialities of the interviewed managers were varied, covering marketing/sales, IS/IT, engineering, management, strategy, and finance.

In addition to the interviews, the research utilized observation and documentation. Analyzed documents include annual and internal reports, presentations, and documentation on mobile service related functions. Consistent with Orlikowski (1993), we found this triangulation useful since it allows cross-checking, which strengthens data validity, provides multiple perspectives, and supplies more complementary information.

\subsection{Library Research: Literature Analysis}

The current research has drawn upon key findings from previous research on business models in general, e-business modeling, and, more essentially, on business modeling and service engineering in the telecoms sector. This research is also inspired by previous research on ontologies. We attempt to analyze and synthesize the existing relevant literature and extend it. 


\subsection{Secondary Data}

This paper utilizes existing organizational and business data in the form of statistics, published reports, available case studies, and companies' websites. This kind of data is used to demonstrate some of the claims in the paper.

\subsection{Speculation: Commentary}

As the integration of the research themes (i.e., mobile technology, service design and engineering, business models, and ontology) is novel, so inferences and speculations have sometimes been employed to build arguments and support discussion pertaining to engineering functions of mobile services.

\subsection{Frameworks and Conceptual Models}

The collected data is utilized in this paper to develop logical representations of the phenomenon under investigation in the form of frameworks and conceptual models. Developing a conceptual model is a key activity in ontology engineering (Jarrar et al. 2003; Pinto and Martin 2004). According to Wand and Weber (2002), conceptual models are useful in (1) supporting communications between users and the development team; (2) helping system analysts in understanding the domain under investigation; (3) providing rich input for the design and implementation processes; and (4) documenting the original system requirements for future reference.

The developed ontology is represented using UML class diagrams. This is because there is a strong interest and call in the ontological engineering domain to use UML for ontology representation (e.g., Eriksson and Penker 2000; Guizzardi et al. 2004) as it provides models that are visually rich and easy to use and understand.

\section{V4 Mobile Service Business Model Ontology}

Designing business models of mobile data services is a complex undertaking as it entails a comprehensive examination of many aspects. Based on our analysis we suggest that when designing service business models, telecoms need to address 15 critical concepts, organized in the following four dimensions (see Figure 2): valueproposition, value-network, value-architecture, and value-finance. These dimensions represent the upper-level constructs of our ontology and we term this the $V^{A}$ service business model ontology.

These design concepts (dimensions and elements) are interdependent (see Figure 3). Hence, addressing them separately without taking into consideration their interrelation ships is neither sufficient nor effective. One action or alteration in one concept would normally trigger changes in other concepts so as to keep the service feasible and successful. This is because, for example, what is financially viable may not be viable for value proposition purposes, or may be difficult to configure and maintain, or may even be hard to acquire through the value network. Thus, a holistic alignment and a coherent trade-off amongst the service business model components are necessary. 


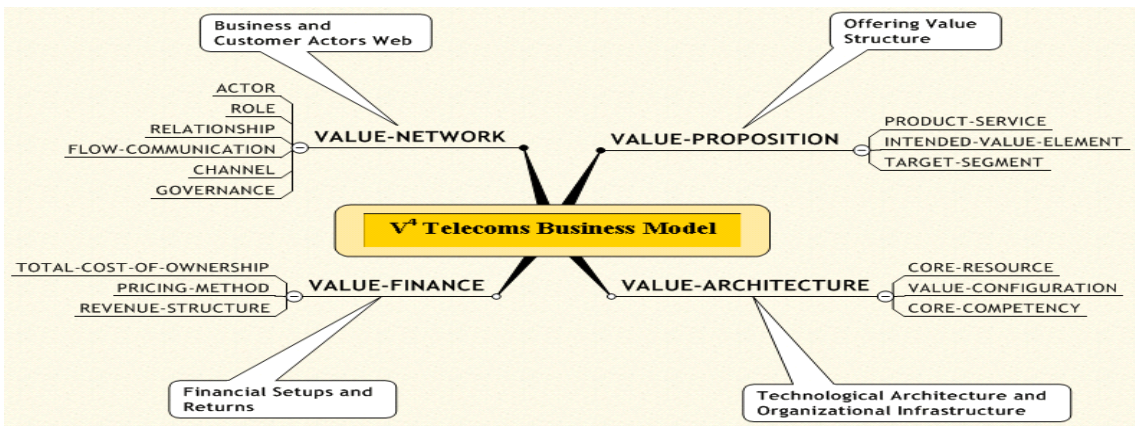

Fig. 2. The Taxonomic Tree of $\mathrm{V}^{4}$ Service Business Model Ontology

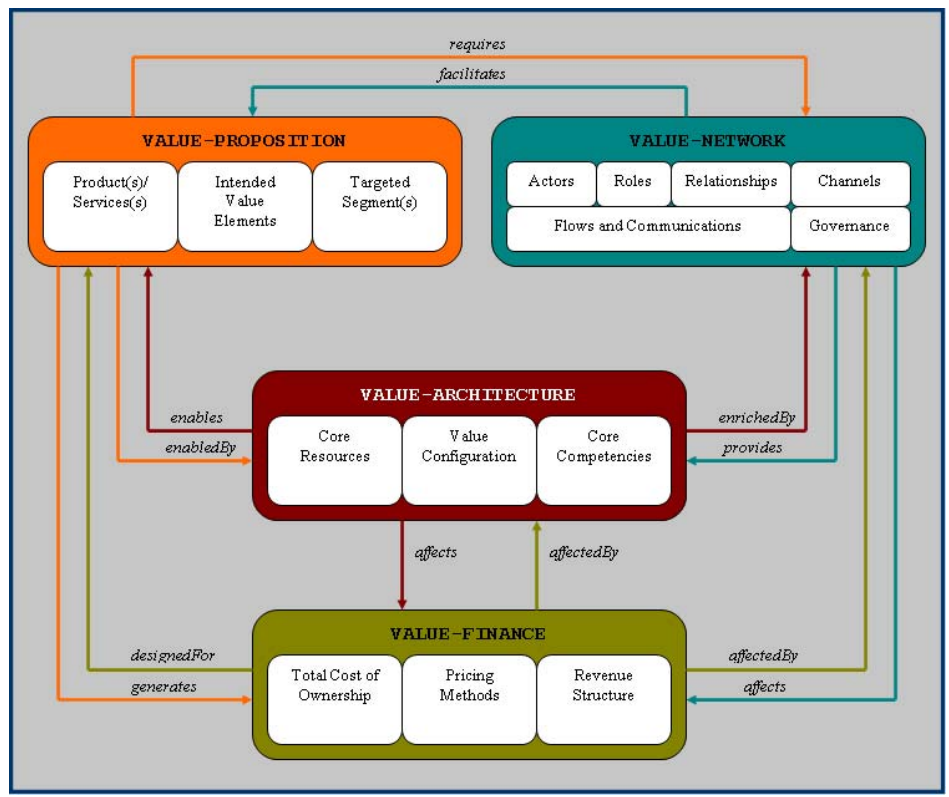

Fig. 3. $V^{4}$ Service Business Model Upper Ontology

In the next subsections, we provide more in-depth discussion for each dimension clarifying the service design concepts and their interdependencies.

\subsection{Value-Proposition}

The value-proposition dimension embraces the first three concepts of designing mobile data services: product-service, intended-value-element, and target-segment (see Figure 4). This refers to the following questions: What is the offering of a particular telecom? What sort of value is incorporated within that offering? Who are the targeted customers that are most likely to desire the proposed offering? 


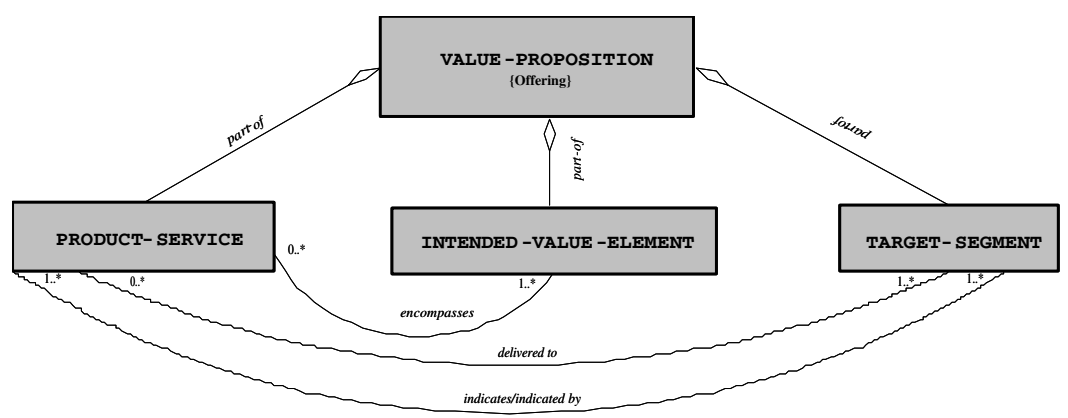

Fig. 4. Value-Proposition Dimension

Product-service. This concept describes the potential service(s) along with the information provided to target segments. New services are described by attributes such as name, type, functions, and technical/nontechnical requirements. Consider this example: Orange offers a service called Click It. This service is categorized as an entertainment service where its main functionality is to provide information on demand. The sort of information the service provides includes the latest in movies, sports news, general news, quotes, and weather forecasts. For customers to utilize this service, they need to be Orange subscribers and to have a phase $2+$ handset device.

This sort of information is useful since (1) it gives an indication about segments seeking and willing to use such services, and (2) it helps in judging a service's feasibility through estimating the size of target segment and matching the features of the service with customer details. For example, Orange estimated that 100,000 of its youth customers are potential users of the Click It service. But if only 10 percent of these customers have phase $2+$ handsets, the size of the target segment is significantly reduced (to 10,000), which will affect service feasibility.

At this phase, it is also of great importance to establish the strategic objective of the new service and to make sure it is consistent with the telecom's overall strategy. There are a number of reasons why services may be designed and launched. For instance, some services are launched to build or sustain the telecom's image in the market, thus primarily not for revenue generation. In some other cases, the target could be to generate cash flow or even to adhere to regulations. Moreover, some services are disruptive while others are ordinary structural services. The reason why the identification of the service objective is significant is that configurations within the design concepts differ substantially across different objectives. Proceeding with the design while objectives of services are unknown is likely to have serious negative consequences.

Intended-value-element. This concept mainly looks at the kinds of value with which telecoms intend to provide customers. Fundamentally, adding value depends on the ability of a telecom to provide customers with services that meet their preferences throughout their life cycle. This is vital since customer satisfaction leads to customer retention and lock-in. Value is basically created when the benefits associated with services are equivalent or exceed the offering's total price where the latter includes search, operating, and disposal costs in addition to the purchase price (Slater and 
Narver 2000). But in the highly competitive market of telecoms, this is not sufficient to guarantee success. Unless delivered values are different or unique, they should surpass those delivered by competitors to win the market.

Broadly speaking, value offered to mobile customers can be categorized as quality or economy. While the design of economy-based values are somehow simple as they only depend on the cost of services in addition to the adopted pricing and billing methods, the design of quality-based values is multifaceted as the assessment criteria of mobile quality of service (QoS) are wide-ranging. Factors related to mobile QoS could be categorized as connection (stability and responsiveness), content (objectivity, believability, amount), interaction (structure, navigation, presentation, design and ease of use, size, color), and contextual (timeliness and promptness) (Chae and Kim 2001). In m-commerce applications, security and privacy are also highlighted and considered key quality factors. Furthermore, quality of life factors (Amanatiadis et al. 2006) in terms of free utilities, which depict friendliness and generosity of a telecom, environment, which shows the extent to which a telecom is acting in an environmentally friendly manner, entertainment, which depicts the sort of amusement that is communicated to users, and public inference related to spectrum allocation are also relevant.

From another standpoint, value can be perceived as utilitarian or hedonic. Utilitarian value is the effective achievement of a utilitarian goal, which is often suitable for customers classified as problem-solvers (Pura 2005). Location-based services is one example of mobile services providing utilitarian values such as identifying the location of a person or finding the nearest petrol station, although sometimes such services provide location-based games that deliver hedonic value. Essentially, hedonic value is delivered when mobile services successfully provide users with fun and enjoyment. Further examples include mobile music and video-clips.

The value delivered by mobile services could also be recognized as emotional in that it fulfils people's needs, for example in relation to status and independence. Technology also plays a role here as it has the potential to deliver what is called epistemic value (see Sheth et al. 1991), enticing customers looking for curiosity and novelty experience as well as new knowledge acquisition. The value of time is also relevant. Users may favor a particular telecom because it provides them with novel services or products faster than does its rivals, or even because the telecom responds to their queries and questions more promptly. In the telecoms sector, there are also very powerful network effects and brand values that can be communicated to customers.

Having discussed different values in the mobile telecommunication sector, the question here is what values should service designers and engineers encapsulate within the new service? Although this issue is complex and we have no straight answer, we suggest that values intended to be delivered to customers should (1) meet the terms of the service objective, (2) comply with the overall strategy and vision of the telecom, (3) be consistent with the target segment nature and behavioral patterns, (4) be able to be delivered efficiently and effectively through the infrastructure, structure, technological architecture, and value system of the telecom, and (5) be positioned successfully both internally, within the existing service portfolio, and externally, within the services offered in the market by other rivals. 
Target-segment. This concept describes the nature of the targeted segment by a particular telecom service. Segmentation of customers implies clustering them into different groups based on shared common properties and characteristics. Segments might involve customers identified as individuals, groups, or organizations. In choosing their desired customers, telecoms could focus on a niche or a mass market. This might be considered a local, regional, or even international marketplace. Usually when customers are individuals, segmentation is done by utilizing their demographic details including income, patterns and trends, and cultural norms. If customers are enterprises, segmentation is done on the basis of one or more factors: enterprise capital, size, revenue generated from the enterprise, sector, industry, and so on.

The high level of dynamics in today's marketplace makes managing and tracking this information one of the most essential aspects to ensure services are successful in their due course. Segmentation is vital since targeting is about choosing profitable clusters. It helps in responding to changes in demand more promptly and effectively. Segmentation is also fruitful in evaluating existing groups or segments, and deciding which one to ignore, add, or cultivate.

\subsection{Value-Network}

The value-network dimension consists of six main design concepts: actor, role, relationship, flow-communication, channel, and governance (see Figure 5). This dimension represents external arrangements that revolve around the communication and collaboration telecoms conduct with others in their value systems including customers, suppliers, allies, business partners, third parties, and intermediaries.

Designing powerful value systems is critical to the success of telecoms services. In explaining why i-mode services are generating high revenues in Japan, while data services in Europe and the United States are struggling, Takeshi Natsuno, the NTT DoCoMo's managing director for i-mode services, argues that the problem is related to market arrangements and structure (Natsuno 2003). He believes that proper value systems that support the creation and delivery of mobile services are still absent in Europe and the United States.

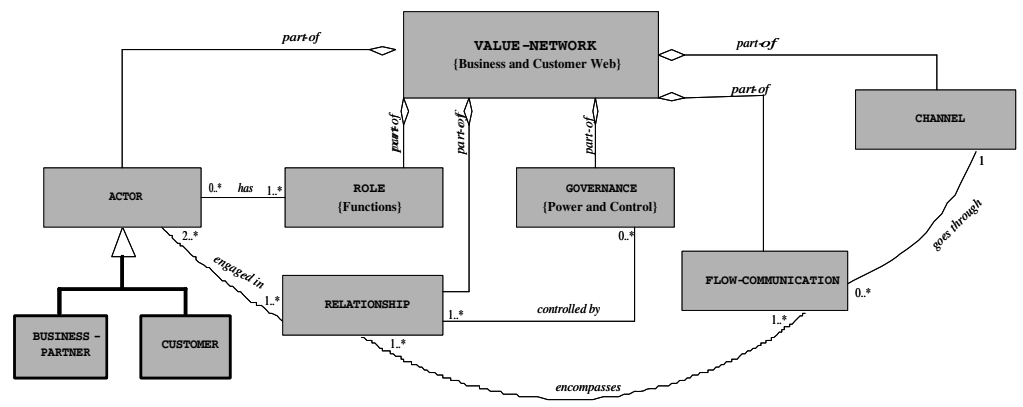

Fig. 5. Value-Network Dimension

Having recognized the importance of this dimension, the developed ontology suggests that telecoms need to examine the six main concepts in order to fruitfully design value networks for mobile data services. 
Actor. This concept is about identifying the core actors with whom the telecom communicates, collaborates, and cooperates in order to launch and deliver a particular service. This not only includes business partners, but also customer actors. Examples of the business actors include engineering equipment vendors, IS/IT application vendors, cellular device manufacturers, content providers, content aggregators, telecoms retailers, and ISPs. As telecommunication regulatory commissions are playing key roles in deriving and shaping the telecoms sector, they are also considered key actors with which telecoms interact. Other actors that might provide complementary services also need to be identified. For example, in the case of provisioning $\mathrm{m}$-commerce services, telecoms establish relationships with actors from the financial sector (e.g., banks) to handle and manage payments.

Role. This concept describes the main role(s) of each actor. While the role of different customers could be simply described as service supplicants, they could also play different, significant roles in service development (see Lacucci et al. 2000). The roles played by enterprise actors are much more varied; thus we here place more emphasis on this issue.

This research distinguishes between functional and strategic roles played by enterprise business actors in the value networks of telecoms. This distinction is based on how telecoms need to recognize the contributions of actors concerning service value creation and the overall success of the telecom. Functional roles are defined from an operational point of view. For example, the functional role of content providers may simply be defined as creating and supplying original content in the form of text, audio, graphics, and video, while the functional role of equipment vendors could be defined as providing cellular infrastructure, devices, applications, and handsets. Understanding roles from this perspective allows a telecom to identify not only its position within the network, but also the position of other actors. Moreover, it helps telecoms in understanding, managing, and controlling its different links with actors.

Other than supplying telecoms with resources, value network actors might also play contributing roles in service provisioning, and mediating roles between the telecom and its target segment in which they provide channels and conduct functions such as distribution, sales, and marketing. They might also perform after-sale functions. Banks may provide a source of finance in terms of loans and credits to establish and run the business. They can also act as payment gateways in which they manage issues related to payments and reconciliations. Regulatory bodies play major roles concerning pricing, entry to market, competition regulations, patents, and intellectual property. The role each actor is playing determines its position within the value system and hence the possible value to be captured.

The strategic roles, on the other hand, refer to what key objectives and benefits a telecom is achieving by having a particular actor within its value network. The combined strategic roles played by all involved actors signify the main motives for telecoms to create and form their own value systems. This research identifies seven main strategic roles.

(1) Resource Allocation: Principally, telecoms may not have sufficient resources to offer competitive and novel services. Thus, they establish relationships with different economic actors to get access to external resources and link them to their own assets. Sometimes, building relationships with particular actors is not 
even a choice but rather a necessity. This is mostly the case when the situation includes factors as rarity of needed resources, patents, and the existence of technological fabrication secrets (Camponovo and Pigneur 2003).

(2) Efficiency: Consistent with transaction-cost theory (see Williamson 1985), telecoms may find it more efficient to collaborate with other business actors to acquire needed resources and specialized skills than possessing all resources on its own.

(3) Risk Mitigation: Especially when the cost of investment is massive and the success is not quite guaranteed, it is advantageous for telecoms to cooperate with partners to create new services rather than doing so alone. This factor has become one of the major motives, particularly after the current economic downturn.

(4) Effectiveness: When designing new services, telecoms may recognize that the service could be launched only by the existing resources and capabilities. If so, however, the new service would lack some important values that are essential to make the service unique and competitive. Telecoms in such cases may find it more effective to add a new actor possessing distinctive resources and capabilities so as to launch competitive, high quality services.

(5) Time-to-Market: The telecommunication sector is highly competitive and timeto-market has become one of the main approaches giving telecoms sustainable competitive advantage by being market leaders and pioneers. Many ideas for new services are shared among telecoms where the role of each is not only to find the most appropriate services to launch, but also importantly to launch services before other rivals do, if it is to become a winner. Retrospectively, telecoms may approach new actors if they could aid in shortening time-to-market of services.

(6) Agility: In the turbulent, dynamic, and fast growing telecommunications sector, a telecom may find value network formation to be the best way of achieving flexibility and providing faster response to changing needs.

(7) Intelligence: Telecoms, through collaboration, cooperation, and joint research and development, can create intelligence in relation to new opportunities and means of creating, delivering, and exchanging advanced value.

However, the expected benefits from participating in such value networks are not achieved easily; as actors pursue different business logic and chase different strategic goals with the collaboration (Bouwman et al. 2008). Therefore, actors need to align their strategic objectives and ensure their consistency so as to capture desired values.

Relationship. This concept is about identifying the sorts of links telecoms establish with their value-network actors. The relationships between telecoms and network actors could take the form of strategic alliances, affiliations, strategic partnerships, joint ventures, or any other sourcing type. The importance of the role each actor plays indicates the kind of relationship the telecom needs to build with that actor. For example, a sourcing relationship seems sensible for acquiring middleware and other software systems, while some sort of strategic partnership appears to be more rational when establishing an association with actors like content and Internet service providers as their roles are more substantial in mobile data services.

The kind of relationships telecoms develop and maintain with their customers represents another facet in this concept. Customers are the main sources of revenue; 
thus creating positive relationship dynamics (Hamel 2000) with them is vital. This helps create customer intimacy and lock-in.

Flow-communication. This concept addresses the material communicated among various actors connected in value networks. Hence, it helps services designers in representing value exchange streams among service economic actors so as to make them more controllable, manageable, and effective.

Relationships with different actors are enriched by materials communicated between them. These materials can take the form of information, knowledge, money, products/ services, hardware, software, documents, agreements, and any other relevant objects. There are two scenarios for materials communication or flow: materials flowing between telecoms and customers, and materials flowing between telecoms and enterprise actors. In the former case, consider this example: Telecoms create intelligence by collecting information about potential customers. Consequently, they provide them with purposeful services. In response, customers allow telecoms along with other network actors to capture value through communicating money and providing other benefits such as feedback information. In the latter case, consider this example: Content flows from content provider to content aggregator. The aggregator cleans, formats, edits, customizes, and combines relevant content and communicates it to telecoms to be used by services. After revenue is generated, each participating actor receives its share from the captured value.

Channel. This concept describes the communication mediums or ports used to communicate materials among actors as a result of their established relationships. Channels could be physical or electronic, and can range from manual to fully automated, where the technological systems talk directly to each other. It is important for telecoms to employ varied channels since communication ports are used with different actors for different functions such as customer relationship management, service delivery, collaboration and communication, distribution and logistics, customer service, and marketing.

Furthermore, arrangements in value networks include constructing interfaces with customers. In addition to physical communication channels including intermediaries, telecoms are exploiting the Internet and other associated technologies such as portals and CRM tools to develop valuable virtual communication mechanisms with their customers. The number, type, customer reach capabilities, and the quality of communication channels telecoms build and maintain with their customers are critical to success.

This design concept is highly related to the former one as service designers and engineers need to select the most appropriate channel at each single flow of materials. For example, information concerning potential customers could be communicated virtually to telecoms using software agents as channels; while to communicate particular mobile services to customers, special handsets maybe used as the communication medium.

Governance. This concept examines the powers and controls of each actor within value networks. Governance tells who has which form of control and power over what kind of objects (e.g., data, relationships, channels, functions, and transactions). Typically, actors try to achieve more power and control in order to augment the value captured. Keeping track of this sort of information is important as telecoms could 
utilize it to identify new opportunities where they can have more power and control, evaluate risks associated with existing configuration of governance, and establish reference points for accountability purposes.

\subsection{Value-Architecture}

The value-architecture dimension adds three new, important concepts when designing new mobile data services: core-resource, value-configuration, and core-competency (see Figure 6). In this context, value-architecture can be defined as a broad plan that specifies all necessary (1) technological architecture arrangements that enable mobile communications to operate efficiently and effectively, and (2) organizational infrastructure arrangements including a telecom structure, key processes and functions, task force, management mindsets, and culture that are needed to enable telecom service provisioning as desired.

The applied analysis in this research reveals that for telecoms to tackle the aforementioned aspects appropriately, they need to examine the following design concepts.

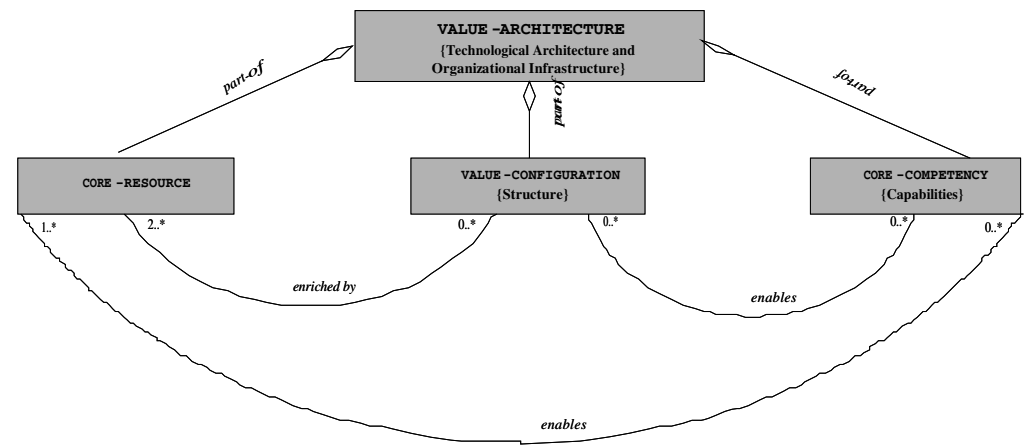

Fig. 6. Value-Architecture Dimension

Core-resource. This concept is about examining and creating useful information of the needed assets and resources to develop new services. The resource-based view (see Barney 2001; Wernerfelt 1984) is highly relevant in this context. The resource-based view assumes that each firm is a bundle of resources. Specifically, it puts emphasis on the strategic importance of resources coupled with their integration and configuration to the generation of capabilities or core competencies and thus sustainable competitive advantages to the firm.

In mobile services, core resources are viewed as cornerstones for value creation. Offering what is valued by telecom customers in the value-proposition dimension requires adequate and appropriate resources in the value-architecture dimension. To be more concise in explaining the aforementioned association we limit the following discussion by considering only cellular infrastructure.

To give just a general overview, the first generation (1G) of cellular technology can only provide voice cellular service. The second generation (2G) is a digital cellular technology that not only enhanced the cellular network capacity in general, but also introduced text messaging (SMS) as the first data service in cellular 
technology. This shift from a voice-centered to a data-centered cellular telecom industry has been enriched by the introduction of $2.5 \mathrm{G}$ cellular technology, which is an "always on" technology that adds valuable data services such as web browsing, location-based services, and audio/video downloading. The delivery of voice and advanced data services coupled with high speed has been introduced in the third generation $(3 \mathrm{G})$ of cellular technology. $4 \mathrm{G}$ is an IP-based integrated system capable of providing premium speed, quality, and security. Moreover, it is worth mentioning here that the deployed cellular technology not only affects the type and quality of services offered, but also determines the possible pricing methods. For example, GSM (2G) cellular networks support only per-minute and flat-rate charging models (Olla and Patel 2002).

At this stage of design, the main role of service engineers is to identify and classify core resources along with their characteristics. As for classifications, the developed ontology distinguishes human, organizational, informational, physical, financial, legal, and relational (Seppänen and Mäkinen 2007), in addition to technological types of resources. Also at this point of design, it is essential to connect resources with the specific services to which they contribute. This is because the value can be optimized for the customer and the firm by identifying the link between a specific resource and a specific service (Pynnönen 2008).

Value-configuration. This concept refers to the ability of telecoms to fruitfully integrate organizational and technological core resources in a way that allows efficient and effective roll-out of successful services. New sources of value are generated through novel deployments of resources (Moran and Ghoshal 1996). To create new or to revamp existing services, it is sometimes sufficient for telecoms to restructure and reorganize their existing resources. In other cases, however, they also need to combine and integrate new sort of resources.

The value-configuration concept is important in mobile service design. This is because unless resources are constantly superior, acquiring and possessing them would not directly allow telecoms to create unique value and gain competitive advantage. It is the manner in which resources are continuously utilized, deployed, and configured within existing structures, culture, and other organizational and technological characteristics that normally gives sustainable competitive advantage. We consider value-configuration as a key enabler of combinative capabilities (Koruna 2004) and core competencies that are important in enabling telecoms to conduct their business more effectively than do their rivals.

Given the dynamic nature of the telecom industry, this design concept has also a significant link with dynamic capabilities (Eisenhardt and Martin 2000). Dynamic capabilities refer to the ability of a firm to transform its resource base to fit the changing nature of the market including customers as well as the industry to which the firm belongs. This transformation ability is based on learning processes (Teece et al. 1997) on how and when firms should create, integrate, (re)combine, (re)configure, and release resources.

However, telecoms at this stage of design need to identify and examine the key processes by which a number of resources are linked and configured in a way that allows core competencies to emerge. This indicates that links need to be established between resources and key processes, then with core competencies, before being finally linked to new services along with their values. Equally important is the link 
between core business processes and the customer journey. This is essential as customers go through many phases throughout their life span that call for different supplies. Thus, telecoms must ensure the existence of effective processes guiding, supporting and leveraging each of these phases. Any misalignment here would cause huge losses to telecoms.

Core-competency. This concept holds information about the range of core competencies or capabilities a particular telecom possesses. Core competencies (see Prahalad and Hamel 1990) could be identified by examining what the telecom can do more efficiently and effectively than its competitors. Core competencies can also be viewed as repeatable patterns of action in the use of assets and the deployment of acquired resources to create and offer services to target segments (Osterwalder and Pigneur 2002).

Three core competency approaches (after Ballon 2007; Treacy and Wiersema 1993) have been identified to reach optimal customer value.

(1) Operational Excellence: The efficiency of telecoms in conducting their internal and interorganizational processes and operations. This efficiency allows cost savings which if translated into competitive prices can attract more customers.

(2) Service Leadership: The effectiveness that refers to the differentiation in the services offered by telecoms. It is the innovative ways in which new services are configured and packaged that give premium quality. This quality could be due to organizational infrastructure, technological architecture, or a combination of the two. Often, innovative services are the result of extensive research and development efforts, which play a key role in determining the nature of values offered to customers. This may lead to offering unique services that are difficult to imitate by rivals. Technological competency in particular may provide substantial enhancements to QoS such as reliability, availability, and performance in general.

(3) Customer Intimacy: The customer experience builds customers intimacy, or not. When telecoms cannot afford any of the prior strategies, customer experience becomes the main and sole competitive weapon. Telecoms need to address customer relationship management to provide customer intimacy and ensure their loyalty and retention.

When core competencies are created through the aforementioned approaches, telecoms need to guarantee the consistency between the approach undertaken and the overall strategy. By referring to Porter's (1980) classification of strategies, we argue that operational excellence fits well those operators following cost-leadership strategy, while product leadership fits well telecoms having differentiation as their principal strategy. Customer intimacy is the preferred approach for both strategy since it is very important to retain customers.

At this point of design, services designers should identify the core competencies along with their complexity levels. Thereafter, fundamental links should be established between the core competencies of the telecom and the intended value elements to be communicated to customers through the offered services. 


\subsection{Value-Finance}

The value-finance dimension is composed of three main design concepts: total-costof-ownership, pricing-method, and revenue-structure (see Figure 7). Value-finance is a description of the core arrangements needed to ensure the economic viability of the offering which includes costing and pricing methods. It also describes the way in which a telecom seeks to generate revenue from its offerings (Timmers 1998), and how this revenue is shared among different stakeholders.

Total-cost-of-ownership. This concept is fundamental as it deals with financial information about the overall costs with respect to all core arrangements that are needed to create, provide, market, deliver, and maintain mobile services throughout their life spans. Total-cost-of-ownership not only includes the cost of tangible materials, but also covers the cost of development, support, and maintenance, as well as the cost of collaboration between telecoms and other value network players. Therefore, this concept represents the entire cost of any telecom service including both the fixed and the variable costs. The weight of this design concept refers to its significance in service pricing.

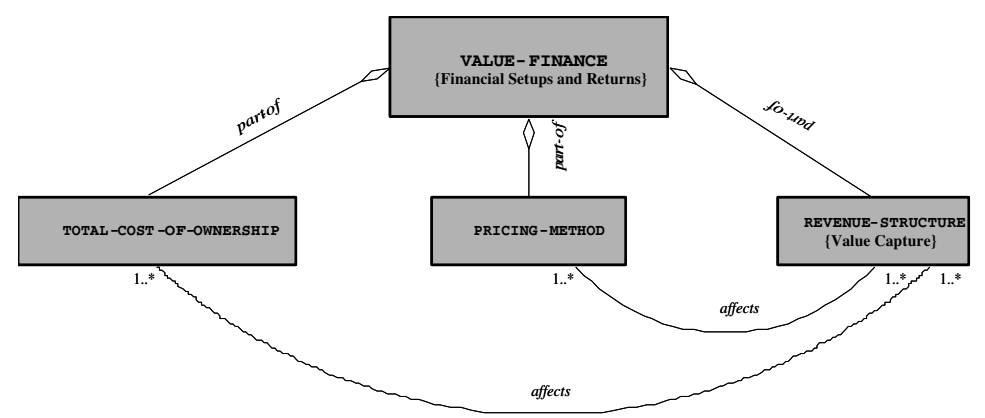

Fig. 7. Value-Finance Dimension

Pricing-method. This concept holds information about the prices of different telecom services along with the employed pricing mechanisms and billing methods. Pricing methods in the telecoms sector can be generally classified as fixed, dynamic, or a mixture of both. Fixed pricing-method implies that customers pay from time to time a certain amount of money to get a predetermined use of certain services and facilities. Typically, fixed pricing is applied in the form of contracts and packaged services. On the other hand, dynamic pricing implies that the price of a certain service differs across usage levels. This research distinguishes time-based, transaction-based, and volume-based as three subcategories of dynamic pricing methods. For example, surfing the Internet using your handset and being charged on the basis of the number of minutes is an example of the time-based pricing method, while charges based on the number of downloads is an example of the transaction-based method. If the charges are on the basis of the size of downloaded files, then it is the volume-based pricing method. 

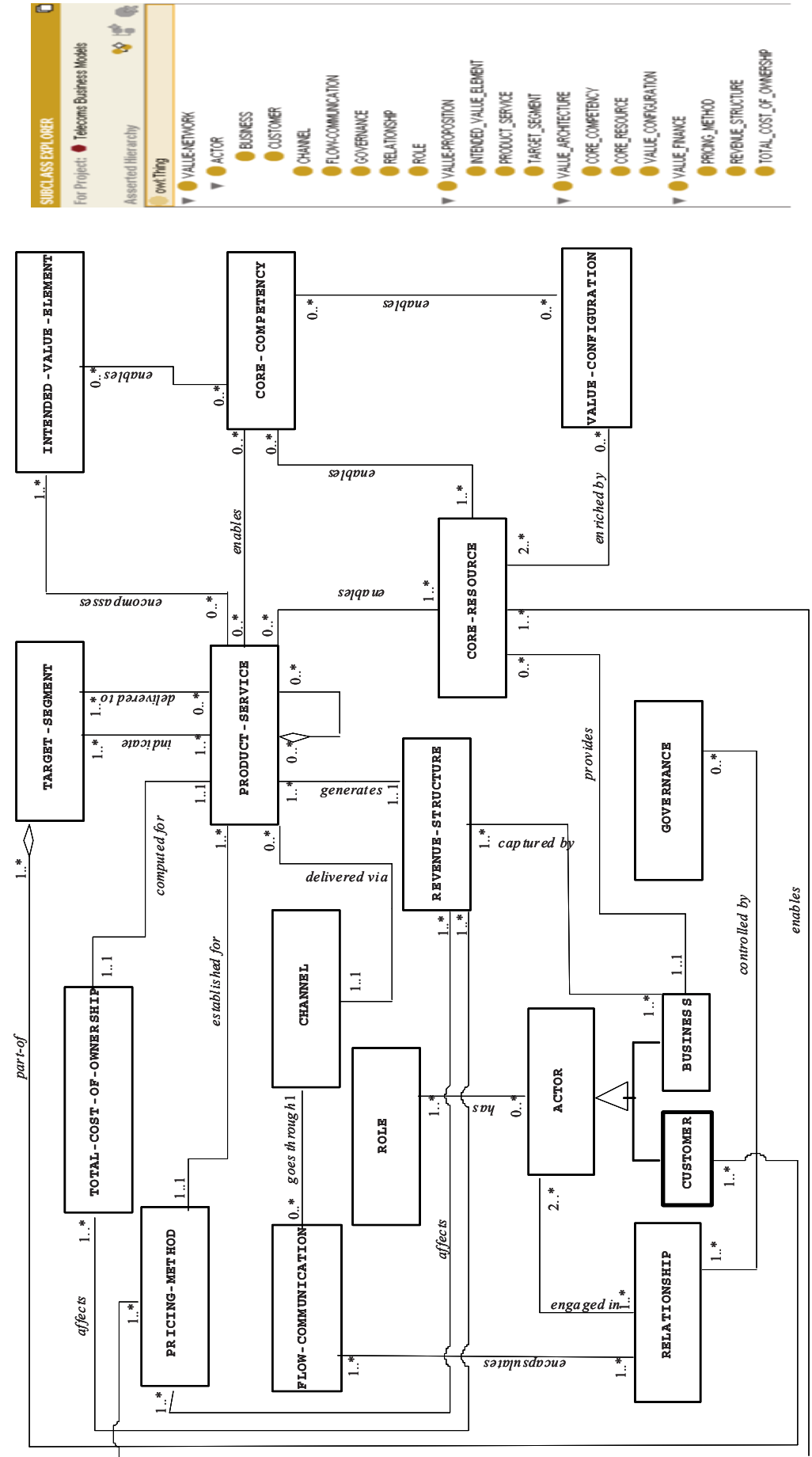

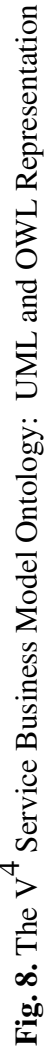


The role of service designers here is not only to set up fitting prices for the new services, but also to choose an appropriate pricing method. This is complex, as many factors affect the pricing of any mobile data service. Nonetheless, we argue that aspects related to the new service objective, total-cost-of-ownership, uniqueness and other features, category, perceived value by customers, affordability, competition level in the market, and whether the service is offered individually or within a bundle of other services are extremely important in guiding the design in this particular concept.

Revenue-structure. This concept contains information concerning generated revenue. It portrays the profitability of different service classes across customer segments. The concept of revenue-structure also shows how the generated revenue is broken down among different economic participating actors. The distributions of costs, risks, and revenues should be made explicit and the way in which revenue is divided among the economic actors should reflect the division of costs and risks.

The volume of the generated revenue is important to telecoms. It ensures the financial sustainability and competitiveness of the telecom. Furthermore, it encourages further investments and leaves greater room for research and development. The revenue generated through a service over a period of time gives an indication of the telecom's ability to translate the value underpinned by technological innovations to financial and economic values. In other words, it indicates the level of the service business model appropriateness at that point in time.

After examining the developed ontology, we now sum up our discussion by providing a cohesive representation of the design concepts and their interdependencies in Figure 8.

\section{Conclusions}

This paper examines mobile service design and engineering from an inclusive view: utilizing the business model concept as a method to structure related critical functions. In a rigorous and semantically rich approach, the $\mathrm{V}^{4}$ ontology has been developed to unambiguously define dimensions, elements, properties, and semantics of service business models. The contribution comes from the novel integration of relevant research topics that provides a harmonized ontology extending current research and taking an important step toward systemizing and leveraging mobile service design and engineering functions.

This research spells out the business model concept as a coherent framework for mobile service design as it provides a holistic view of a particular business, which is not only useful in understanding the internal structure and functions, but also in realizing how telecoms are connected to their external environment and how they interact with it. This research demonstrates that designing new mobile data services requires the examination of their value proposition issues and looking closely at the service definition as well as matching the patterns and trends of the target segments with the value elements of the services. To engineer successful mobile services, it is also vital to have a strong technological architecture capable of providing high quality of service standards, as well as a suitable organizational infrastructure, including appropriate managerial mindsets. 
Delineating the communication and collaboration issues telecoms have with various actors is also crucial, because the structure of the telecom industry is shifting from an autocratic state to a more democratic one, where a more complex and open system, including extensive collaboration, communication, and cooperation are prevalent. The consideration of the service financial aspects including total cost of ownership, pricing methods, and revenue models is also clearly fundamental. In addition, and in view of the fact that different aspects of service engineering are interrelated, this research reveals that it is also important to look at these aspects cohesively and to consider their interdependencies.

The developed ontology contributes to both theory and practice and provides a complete foundational framework for mobile service design and engineering. It is of value to academics and practitioners alike, particularly those interested in the strategic-oriented IS/IT and business developments of telecoms. The developed ontology not only provides a common language and terminology amongst information systems and software agents to enhance their interoperability, but also amongst people. Furthermore, the $\mathrm{V}^{4}$ ontology enables capturing and reusing of applicationindependent knowledge and semantics (i.e., knowledge reuse rather than software reuse). From a practical perspective, this comprehensive ontology enhances the ability of telecoms to design, create, communicate, compare, analyze, evaluate, and modify their existing and future mobile data services, using a systematic and effective approach.

While this ontology has been developed specifically for mobile data services, we argue that it would be equally appropriate to the design and engineering of other technological artifacts (e.g., eServices, broadband services, telecom services and products, etc.). Indeed, the $\mathrm{V}^{4}$ service business model ontology has been the preferred method of one Latin American company to design and develop not only a mobile business application, but also an eApplication for business. Due to the restrictions of space, this paper does not provide all of the details of the data collected and analyzed; it only highlights the major results and we have concentrated on defining and discussing the $\mathrm{V}^{4}$ business model ontology for service design and engineering as being the main contribution.

\section{References}

Afuah, A., Tucci, C.: Internet Business Models and Strategies, 2nd edn. McGraw-Hill, New York (2003)

Al-Debei, M.M., Avison, D.: Business Model Requirements and Challenges in the Mobile Telecommunication Sector. Journal of Organizational Transformation and Social Change (forthcoming, 2010)

Al-Debei, M.M., El-Haddadeh, R., Avison, D.: Defining the Business Model in the New World of Digital Business. In: Proceedings of the 14th Americas Conference on Information Systems, AMCIS 2008, Toronto, Canada, August 14-17 (2008a)

Al-Debei, M.M., El-Haddadeh, R., Avison, D.: Towards a Business Model for Cellular Networks and Telecommunication Operators: A Theoretical Framework. In: Proceedings of the 13th Conference of the UK Academy for Information Systems, Bournemouth, UK (2008b) 
Al-Debei, M.M., Fitzgerald, G.: OntoEng: A Design Method for Ontology Engineering in Information Systems. In: ACM OOPSLA'0 - Ontology-Engineering Software Engineering Workshop, Orlando, Florida, October 25-29 (2009)

Amanatiadis, A., Drakatos, K., Tsironis, L., Moustakis, V.: Defining the Main Factors of Quality of Service in Mobile Telephony. In: Proceedings of Second International Conference on Wireless and Mobile Communications, Bucharest, Romania, July 29-31 (2006)

Andersson, B., Bergholtz, M., Edirisuriya, A., Ilayperuma, I., Johannesson, P., Grégoire, B., Schmitt, M., Dubois, E., Abels, S., Hahn, A., Gordijn, J., Weigand, H., Wangler, B.: Towards a Reference Ontology for Business Models. In: Proceedings of the 25th International Conference on Conceptual Modeling, Tucson, Arizona, November 6-9 (2006)

Ballon, P.: Business Modeling Revisited: The Configuration of Control and Value. Info-The Journal of Policy, Regulation and Strategy for Telecommunications 9(5), 6-19 (2007)

Barney, J.B.: Resource-Based Theories of Competitive Advantage: A Ten-Year Retrospective on the Resource-Based View. Journal of Management 27(6), 643-650 (2001)

Bouwman, H., De Vos, H., Haaker, T.: Mobile Service Innovation and Business Models. Springer, Berlin (2008)

Bullinger, H.J., Fahnrich, K.P., Meiren, T.: Service Engineering-Methodical Development of Service Products. International Journal of Production Economics 85(3), 275-287 (2003)

Campanovo, G., Pigneur, Y.: Business Model Analysis Applied to Mobile Business. In: Proceedings of the Fifth International Conference on Enterprise Information Systems, Angers, France, April 23-26 (2003)

Chae, M., Kim, J.: Information Quality for Mobile Internet Services: A Theoretical Model with Empirical Validation. In: Storey, V.C., Sarkar, S., DeGross, J.I. (eds.) Proceedings of 22nd International Conference on Information Systems, New Orleans, LA, December 16-19, pp. 43-53 (2001)

Chandrasekaran, B., Josephson, J.R., Benjamins, V.R.: What Are Ontologies, and Why Do We Need Them? IEEE Intelligent Systems and Their Applications 14(1), 20-26 (1999)

Chesbrough, H.W., Rosenbloom, R.S.: The Role of The Business Model in Capturing Value from Innovation: Evidence from Xerox Corporation's Technology Spin-Off Companies. Industrial and Corporate Change 11(3), 529-555 (2002)

Dodourova, M.: Industry Dynamics and Strategic Positioning in the Wireless Telecommunications Industry: The Case of Vodafone Group Plc. Management Decision 41(9), 859-870 (2003)

Eisenhardt, K.M., Martin, J.A.: Dynamic Capabilities: What Are They? Strategic Management Journal 21(10-11), 1105-1121 (2000)

Eriksson, H.E., Penker, M.: Business Modeling with UML. John Wiley, New York (2000)

Gordijn, J., Akkermanns, J.M.: Designing and Evaluating eBusiness Models. IEEE Intelligent Systems 16(4), 11-17 (2001)

Gruber, T.R.: A Translation Approach to Potable Ontology Specification. Knowledge Acquisition 5(2), 199-220 (1993)

Guarino, N.: Formal Ontology in Information Systems. IOS Press, Amsterdam (1998)

Guarino, N., Welty, C.: Evaluating Ontological Decisions with OntoClean. Communications of the ACM 45(2), 61-65 (2002)

Guizzardi, G., Wanger, G., Guarino, N., Van Sinderen, M.: An Ontologically Well-Founded Profile for UML Conceptual Models. In: Persson, A., Stirna, J. (eds.) CAiSE 2004. LNCS, vol. 3084, pp. 112-126. Springer, Heidelberg (2004)

Hamel, G.: Leading the Revolution. Harvard Business School Press, Boston (2000)

Hedman, J., Kalling, T.: The Business Model Concept: Theoretical Underpinnings and Empirical Illustrations. European Journal of Information Systems 12(1), 49-59 (2003) 
Hevner, A.R., March, S.T., Park, J., Ram, S.: Design Science in Information Systems Research. MIS Quarterly 28(1), 75-105 (2004)

ITU. Measuring the Information Society, International Telecommunications Union (2009), http://www.itu.int/ITU-D/ict/publications/idi/2009/ index.html (accessed June 20, 2009)

Jarrar, M., Demey, J., Meersman, R.: On Using Conceptual Data Modeling for Ontology Engineering. In: Spaccapietra, S., March, S., Aberer, K. (eds.) Journal on Data Semantics I. LNCS, vol. 2800, pp. 185-207. Springer, Heidelberg (2003)

Kamoun, F.: Rethinking the Business Model with RFID. Communications of the AIS 22(1), 635-658 (2008)

Kim, Y., Lee, Y., Kong, G., Yun, H., Chang, S.: A New Framework for Designing Business Models in Digital Ecosystem. In: Proceedings of Second IEEE International Conference on Digital Ecosystems and Technologies, Phitsanulok, Thailand, February 26-29, pp. 281 287 (2008)

Kishore, R., Sharman, R.: Computational Ontologies and Information Systems I: Foundations. Communications of the Association for Information Systems 14(8), 158-183 (2004)

Koruna, S.: Leveraging Knowledge Assets: Combinative Capabilities - Theory and Practice. R\&D Management 34(5), 505-516 (2004)

Kumar, V., Parimi, S., Agarwal, D.P.: WAP: Present and Future. IEEE Pervasive Computing 2(1), 79-83 (2003)

Lacucci, G., Kuutti, K., Ranta, M.: On the Move with a Magic Thing: Role Playing in Concept Design of Mobile Services and Devices. In: Boyarski, D., Kellogg, W.A. (eds.) Proceedings of Third Conference on Designing Interactive Systems: Processes, Practices, Methods, and Techniques, New York, August 17-19, pp. 193-202 (2000)

Linder, J., Cantrell, S.: Changing Business Models: Surveying the Landscape. Working Paper, Accenture Institute for Strategic Change, Cambridge, MA (2000)

MacInnes, I.: Dynamic Business Model Framework for Emerging Technologies. International Journal of Service Technology and Management 6(1), 3-19 (2005)

Magretta, J.: Why Business Models Matter. Harvard Business Review 80(5), 86-92 (2002)

Maitland, C.F., Van De Kar, E.A.M., De Montalvo, U.W., Bouwman, H.: Mobile Information and Entertainment Services: Business Models and Service Networks. International Journal of Management and Decision Making 6(1), 47-64 (2005)

March, S.T., Smith, G.F.: Design and Natural Science Research on Information Technology. Decision Support Systems 15(4), 251-266 (1995)

Mingers, J.: Combining IS Research Methods: Towards a Pluralist Methodology. Information Systems Research 12(3), 240-259 (2001)

Moran, P., Ghoshal, S.: Value Creation by Firms. In: Academy of Management Best Paper Proceedings, pp. 41-45 (1996)

Natsuno, T.: The i-Mode Wireless Ecosystem. Wiley, Yokohama (2003)

Olla, P., Patel, N.V.: A Value Chain Model for Mobile Data Service Providers. Telecommunications Policy 26(9-10), 551-571 (2002)

Orlikowski, W.J.: CASE Tools as Organizational Change: Investigating Incremental and Radical Changes in Systems Development. MIS Quarterly 17(3), 309-340 (1993)

Osterwalder, A., Pigneur, Y.: An e-Business Model Ontology for Modeling e-Business. In: Proceedings of the 15th Bled Electronic Commerce Conference, Bled, Slovenia, June 1719 (2002)

Osterwalder, A., Pigneur, Y., Tucci, C.L.: Clarifying Business Models: Origins, Present, and Future of the Concept. Communications of the AIS 15, 2-40 (2005) 
Palvia, P., Midha, V., Pinjani, P.: Research Models in Information Systems. Communications of the AIS 17(1), 1042-1063 (2006)

Pinto, H.S., Martins, J.P.: Ontologies: How Can They Be Built? Knowledge and Information Systems 6(4), 441-464 (2004)

Porter, M.E.: Competitive Strategy. The Free Press, New York (1980)

Prahalad, C.K., Hamel, G.: The Core Competence of the Corporation. Harvard Business Review 68(3), 79-91 (1990)

Pura, M.: Linking Perceived Value and Loyalty in Location-Based Mobile Services. Managing Service Quality 15(6), 509-538 (2005)

Pynnönen, M.: Customer Lock-In in ICT Services Business: Designing and Managing Customer Driven Business Model. In: Proceedings of International Conference on Management of Engineering \& Technology, Porland, Oregon, July 27-31, pp. 818-828 (2008)

Ratliff, J.M.: NTT DoCoMo and its i-Mode Success. California Management Review 44(3), 55-71 (2002)

Seddon, P.B., Lewis, G., Freeman, P., Shanks, G.: Business Models and Their Relationship to Strategy. In: Currie, E. (ed.) Value Creation from e-Business Models, pp. 11-34. Butterworth-Heinemann, Oxford (2004)

Seppänen, M., Mäkinen, S.: Assessing Business Model Concepts with Taxonomical Research Criteria. Management Research News 30(10), 735-748 (2007)

Sheth, J., Newman, B., Gross, B.: Consumption Values and Market Choices: Theory and Applications. South-Western Publishing Co., Cincinnati (1991)

Sigurdson, J.: WAP OFF: Origin, Failure, and Future, Working Paper No. 135, Stockholm School of Economics, Stockholm, Sweden (2001)

Slater, S.F., Narver, J.C.: Intelligence Generation and Superior Customer Value. Journal of the Academy of Marketing Science 28(1), 120-127 (2000)

Smith, B.: Ontology. In: Floridi, L. (ed.) The Blackwell Guide to the Philosophy of Computing and Information, pp. 155-166. Blackwell, Malden (2003)

Teece, D.J., Pisano, G., Shuen, A.: Dynamic Capabilities and Strategic Management. Strategic Management Journal 18(7), 509-533 (1997)

Timmers, P.: Business Models for Electronic Markets. Electronic Markets 8(2), 3-8 (1998)

Treacy, M., Wiersema, F.: Customer Intimacy and Other Value Disciplines. Harvard Business Review 71(1), 84-93 (1993)

Wand, Y., Weber, R.: An Ontological Model of an Information System. IEEE Transactions on Software Engineering 16(11), 1282-1292 (1990)

Wand, Y., Weber, R.: Research Commentary: Information Systems and Conceptual Modeling-A Research Agenda. Information Systems Research 13(4), 363-376 (2002)

Wernerfelt, B.: A Resource-Based View of the Firm. Strategic Management Journal 5(2), 171$180(1984)$

Williamson, O.E.: The Economic Institutions of Capitalism. Free Press, New York (1985)

Wyssusek, B.: Ontology and Ontologies in Information Systems Analysis and Design: A Critique. In: Proceedings of the 10th Americas Conference on Information Systems, New York, August 6-8, pp. 4303-4308 (2004)

Yuan, Y., Zhang, J.J.: Towards an Appropriate Business Model for m-Commerce. International Journal of Mobile Communications 1(1-2), 35-56 (2003)

\section{About the Authors}

Mutaz M. Al-Debei is a Ph.D. student and teaching assistant at Brunel University's School of Information Systems and Computing. His research interests include the 
design and engineering of mobile (cellular) services and other technological artifacts from business model and design science perspectives. Al-Debei holds a B.Sc. in Computer Engineering and an MBA with an IS concentration. He also has more than 10 years of IT industry experience, having worked in Jordan for the Royal Scientific Society, Jordan National Bank, MasterCard, and Arab Radio and Television, as well as lecturing at the University of Jordan and Al-Ahliyya University. He is a trainer for a number of professional certificates such as OCP for Oracle Developers and DBAs, MCSE, Security+, Network+, CCNA, and Credit Card Frauds. He can be reached at Mutaz.Al-Debei@brunel.ac.uk.

Guy Fitzgerald is Professor of Information Systems in the Department of Information Systems and Computing (DISC) at Brunel University. Before this he was the Cable \& Wireless Professor of Business Information Systems at Birkbeck College, University of London, and prior to that he was at Templeton College, Oxford. He has also worked in the computer industry with companies such as British Telecom, Mitsubishi, and CACI Inc, International. His research interests are concerned with the effective management and development of information systems and he has published widely in these areas. He has undertaken a number of cases studies in organizations that have used information systems to enable significant organizational transformation. He has also undertaken research in relation to strategy, executive information systems, outsourcing, and flexibility. He is founder and coeditor, with David Avison, of the Information Systems Journal from Blackwell/Wiley, is author of a well known text book on information systems development methodologies, and is currently the elected Vice-President of Publications for the Association for Information Systems. He can be reached at Guy.Fitzgerald@brunel.ac.uk. 